\title{
MODEL BLACK-SCHOLES OPSI CALL DAN OPSI PUT TIPE EROPA DENGAN DIVIDEN PADA KEADAAN CONSTANT MARKET
}

\author{
ELSA WAHYUNI, RIRI LESTARI, MAHDHIVAN SYAFWAN \\ Program Studi Matematika, \\ Fakultas Matematika dan Ilmu Pengetahuan Alam, Universitas Andalas, \\ Kampus UNAND Limau Manis Padang, Indonesia, \\ email : wahyunielsa04@gmail.com
}

\begin{abstract}
Abstrak. Opsi tipe Eropa adalah suatu bentuk perjanjian berupa kontrak yang memberikan pemegang opsi suatu hak tetapi bukan suatu kewajiban untuk membeli atau menjual aset tertentu dengan harga tertentu pada waktu jatuh tempo. Opsi call memberikan hak kepada pemegang opsi untuk membeli saham pada waktu jatuh tempo. Sementara opsi put memberikan hak untuk menjual saham. Metode Black-Scholes merupakan salah satu metode untuk menentukan harga opsi. Asumsi yang digunakan pada model ini adalah adanya pembagian dividen. Dividen dibayarkan pada keadaan constant market. Harga saham yang berubah secara acak menurut waktu diasumsikan sebagai proses stokastik. Prediksi harga saham diasumsikan hanya dipengaruhi oleh harga saham saat ini dan tidak dipengaruhi oleh harga saham di masa lampau. Perhitungan harga opsi saham chevron corporation pada tanggal 16 November 2016 dengan mengaplikasikan model Black-Scholes. Hasil yang diperoleh menunjukkan bahwa pada keadaan constant market sebaiknya investor membeli opsi put di pasar saham dengan harga opsi yang lebih kecil dari harga opsi model Black-Scholes yaitu pada harga pelaksanaan 101, 102, 104, 105, 106, 107 dan 108, sedangkan untuk opsi call sebaiknya investor membeli opsi call di pasar saham untuk harga pelaksanaan 100 dan 101.

Kata Kunci: Opsi tipe Eropa, Opsi call, Opsi put, Proses Stokastik, Dividen, Constant
\end{abstract} Market, Model Black-Scholes

\section{Pendahuluan}

Perkembangan ekonomi dan keuangan pada zaman sekarang ini menjadi sorotan bagi kalangan pebisnis, salah satunya adalah perdagangan pasar modal. Pasar modal saat ini menjadi sasaran para investor untuk melakukan berbagai macam bentuk investasi. Investasi sering juga disebut dengan penanaman modal. Suatu peningkatan pendapatan akan mendorong investasi yang lebih besar dengan tingkat bunga yang lebih tinggi [1]. Selain berinvestasi, para investor biasanya juga tertarik untuk membeli lembar saham ataupun lembar opsi.

Ada dua macam kontrak opsi saham, yaitu opsi call dan opsi put. Opsi call adalah tipe kontrak yang memberikan hak untuk membeli sebuah aset pada harga kesepakatan dan dalam jangka waktu tertentu yang disepakati. Sedangkan opsi put adalah tipe kontrak yang memberikan hak untuk menjual sebuah aset pada harga kesepakatan dan dalam jangka waktu yang telah disepakati [1]. Dilihat dari cara pelaksanaan sebuah opsi, terdapat dua tipe opsi yaitu opsi tipe Eropa dan opsi tipe 
Amerika. Opsi tipe Eropa yaitu suatu kontrak opsi yang hanya bisa dilaksanakan pada hari terakhir yaitu pada waktu jatuh tempo berlakunya opsi tersebut. Opsi tipe Amerika yaitu suatu kontrak opsi yang bisa dilaksanakan kapan saja mulai dari tanggal penandatanganan kontrak sampai pada waktu jatuh tempo berlakunya opsi.

Nilai opsi dapat ditentukan dengan menggunakan beberapa model, salah satunya adalah model Black-Scholes. Model Black-Scholes dapat digunakan untuk opsi tipe Eropa dan dilaksanakan pada saat jatuh tempo. Tipe opsi yang digunakan pada penelitian ini adalah opsi tipe Eropa dan tidak terdapat pajak serta biaya transaksi sampai waktu jatuh tempo opsi tersebut [3]. Sebagian besar opsi saham yang diperjualbelikan pada kenyataannya membayarkan dividen. Dividen adalah pembagian keuntungan suatu perusahaaan terhadap para pemegang saham. Jika dividen dibagikan maka akan menurunkan harga opsi. Dividen dibagikan dalam keadaan constant market. Berdasarkan penjelasan di atas, maka penelitian ini membahas tentang Model Black-Scholes Opsi Call dan Opsi Put Tipe Eropa dengan Dividen pada Keadaan Constant Market.

\section{Model untuk Harga Saham}

Harga saham yang berubah secara acak menurut waktu diasumsikan sebagai proses stokastik. Misalkan harga saham dilambangkan dengan $S_{t}$ pada waktu $t$. Pada selang waktu yang kecil $d t$, harga saham $S_{t}$ akan berubah menjadi $S_{t}+d S_{t}$, sehingga tingkat pengembalian saham dilambangkan dengan $\frac{\left(d S_{(t)}\right)}{\left(S_{(t)}\right)}$ yang didefinisikan

$$
\frac{d S_{t}}{S_{t}}=\mu d t+\sigma d W_{t}
$$

dengan $\mu d t$ adalah pengembalian dari harga saham yang bersifat deterministik, $\sigma d W_{t}$ adalah pengembalian dari harga saham yang bersifat stokastik dan $W_{t}$ adalah gerak Brown, serta $\mu$ adalah nilai ekspektasi return atau tingkat rata-rata pertumbuhan harga saham dan $\sigma$ adalah volatilitas harga saham.

\section{Lema Ito}

Misalkan harga dari suatu variabel $x$ memenuhi persamaan differensial stokastik

$$
d x=a(x, t) d t+b(x, t) d W_{t} .
$$

Lema Ito mengikuti proses berikut

$$
\partial f=\left(\frac{\partial f}{\partial x} \alpha+\frac{\partial f}{\partial t}+\frac{1}{2} \frac{\partial^{2} f}{\partial x^{2}} b^{2}\right) d t+\frac{\partial f}{\partial x} b d W_{t}
$$

\section{Dividen}

Dividen adalah pembayaran atau pembagian keuntungan oleh perusahaan kepada para pemegang saham. Nilai present value dividen $P V(q)$ adalah

$$
P V(q)=q e^{-r(\tau-t)},
$$

dimana $q$ adalah dividen lembar saham yang akan dibayarkan, $r$ adalah tingkat suku bunga bebas resiko, $t$ adalah ex-dividend. 


\section{Keadaan Constant Market}

Keadaan constant market adalah keadaan kontrak opsi saham dengan suku bunga bebas resiko $r$ konstan dan pengembalian dividen $q$ konstan. Jika perusahaan membagikan dividen, misal dividen pada $t_{1}$ adalah $q_{t_{1}}$, maka harga saham setelah pembagian dividen dirumuskan sebagai berikut

$$
S=E\left(S_{t_{1}}+q e^{\left[-r\left(t_{1}-t\right)\right]}\right) .
$$

harga saham pada saat jatuh tempo akan mengalami penurunan sebesar present value dari dividen yang dibagikan, yaitu

$$
S_{T}=S-q e^{[-r(\tau-t)]} .
$$

Asumsi untuk menentukan nilai opsi beli tipe Eropa dengan pembagian dividen dalam keadaan constant market adalah

(1) Model pergerakan harga saham mengikuti persamaan differensial stokastik.

(2) Tingkat suku bunga bebas resiko sampai waktu jatuh tempo $T$ adalah konstan.

(3) Pada waktu ex-dividend $t \leq T$ perusahaan membagikan dividen (konstan).

(4) Tidak ada biaya transaksi dan pajak.

(5) Pasar bebas Arbitrasi.

Nilai portofolio $\pi$ yang terdiri dari opsi $\bar{c}$ dengan perubahan saham pada jangka pendek, yaitu

$$
\pi=\bar{C}-\frac{\partial \bar{C}}{\partial S_{t}} S_{t}
$$

Perhatikan persamaan (2.1), diperoleh

$$
d S_{t}=\mu S_{t} d t+\sigma S_{t} d W_{t}
$$

Gunakan Lema Ito pada Persamaan (3.1). Misalkan $a(x, t)=a\left(S_{t}, t\right)=\mu S_{t}$ dan $b(x, t)=b\left(S_{t}, t\right)=\sigma S_{t}$. Aplikasikan persamaan (3.1) dengan memisalkan $f\left(S_{t}, t\right)=\ln \left(S_{t}\right)$. Dengan mengaplikasikan Lema Ito, diperoleh persamaan differensial stokastik untuk proses harga saham, yaittu

$$
d S_{t}=\left(\mu-\frac{1}{2} \sigma^{2}\right) S_{t} d t+\sigma S_{t} d W_{t} .
$$

Substitusi nilai $a\left(S_{t}, t\right)$ dan $b\left(S_{t}, t\right)$ dan nilai turunan yang diperoleh dari pemisalan diatas ke persamaan (3.2) dan aplikasikan untuk $\bar{C}(S, t)$ diperoleh

$$
d \bar{C}=\frac{\partial \bar{C}}{\partial t} d t+\frac{\partial \bar{C}}{\partial S_{t}} d S_{t}+\frac{1}{2} \sigma^{2} S_{t}^{2} \frac{\partial^{2} \bar{C}}{\partial S_{t}^{2}} d t
$$

Berdasarkan persamaan (5.6) diperoleh bahwa

$$
d\left(\bar{C}-\frac{\partial \bar{C}}{\partial S_{t}} S_{t}\right)=\frac{\bar{C}}{\partial t} d t+\frac{1}{2} \sigma^{2} S_{t}^{2} \frac{\partial^{2} \bar{C}}{\partial S_{t}^{2}} d t .
$$

Sehingga perubahan nilai portofolio menjadi

$$
d \pi=d\left(\bar{C}-\frac{\partial \bar{C}}{\partial S_{t}} S_{t}\right)=\frac{\partial \bar{C}}{\partial t} d t+\frac{1}{2} \sigma^{2} S_{t}^{2} \frac{\partial^{2} \bar{C}}{\partial S_{t}^{2}} d t
$$


Kedua ruas dari persamaan (5.8) dibagi dengan $d t$, sehingga diperoleh

$$
\frac{d \pi}{d t}=\frac{\partial C}{\partial t}+\frac{1}{2} \sigma^{2} S_{t}^{2} \frac{\partial^{2} C}{\partial S_{t}^{2}}
$$

Nilai perubahan portofolio dengan tidak adanya arbitrasi harus sama dengan suku bunga bebas resiko $r$, nilai perubahan portofolio $d \pi$ yang di investasikan adalah $r d t$ dan jika terjadi pembagian dividen, maka nilai portofolio dapat ditulis dengan

$$
\frac{d \pi}{d t}=r \pi-q \frac{\partial \bar{C}}{\partial S_{t}} S_{t}=r\left(\bar{C}-\frac{\partial \bar{C}}{\partial S_{t}} S_{t}\right)-q \frac{\partial \bar{C}}{\partial S_{t}} S_{t}
$$

Dari persamaan (5.9) dan persamaan (5.10), diperoleh

$$
\frac{\partial \bar{C}}{\partial t}+\frac{1}{2} \sigma^{2} S^{2} \frac{\partial^{2} \bar{C}}{\partial S^{2}} d t+(r-q) \frac{\partial \bar{C}}{\partial S} S_{t}-r C=0
$$

\section{Penurunan Model Black-Scholes Opsi Call dan Opsi Put Tipe Eropa Dengan Dividen Pada Keadaan Constant Market}

Model perubahan harga saham dapat dinyatakan dengan

$$
d S_{t}=r S_{t} d t+\sigma S_{t} d W_{t},
$$

Berdasarkan Persamaan (3.2) diperoleh

$$
d \ln \left(S_{t}\right)=\left(r-\frac{\sigma^{2}}{2}\right) d t+\sigma W_{t}
$$

sehingga

$$
S_{\pi}=S_{0} \exp \left(\left(r-\frac{1}{2} \sigma^{2}\right)(T-t)+\sigma W_{t}\right),
$$

Variabel acak $W_{t}$ adalah berdistribusi normal denga nilai tengah 0 dan variansi $T$. Begitu juga distribusi dari $\sqrt{T} Y$ dimana $Y \sim N(0,1)[2]$.

$$
S_{\tau}=S_{0} \exp \left(\left(r-\frac{1}{2} \sigma^{2}\right)(T-t)+\sigma \sqrt{T} Y\right)
$$

Diasumsikan bahwa semua investor opsi netral terhadap resiko (risk neutral $Q$ ), sehingga nilai opsi put tipe Eropa pada saat t adalah

$$
P(S, t)=e^{-r(\tau-t)} E^{Q}\left[\left(K-S_{\tau}\right)^{+}\right] .
$$

Harga saham setelah pembagian dividen dapat dinyatakan dalam bentuk

$$
S_{0}=S-q e^{-r(\tau-t)} .
$$

Jika pembagian dividen dilaksanakan pada waktu jatuh tempo $T$ dan $P V(q)=$ $q e^{-r(\tau-t)}$ maka diperoleh

$$
S_{\tau}=(S-P V(q)) e^{\left(r-\frac{1}{2} \sigma^{2}\right)(\tau-t)+\sigma \sqrt{T-t} Y}
$$


dengan $S_{0}=S-P V(q)$. Berdasarkan persamaan (6.5) dapat ditulis

$$
\begin{aligned}
& P(S, t)=e^{-r(T-t)} E^{Q}\left[\left(K-\left((S-P V(q)) e^{\left(r-\frac{1}{2} \sigma^{2}\right)(T-t)+\sigma \sqrt{T-t} Y}\right)\right)^{+}\right] \\
& =e^{-r(\tau-t)} \int_{x}^{\infty} \frac{1}{\sqrt{2 \pi}}\left(K-\left((S-P V(q)) e^{\left(r-\frac{1}{2} \sigma^{2}\right)(T-t)+\sigma \sqrt{T-t} X}\right)\right)^{+} e^{-\frac{x^{2}}{2}(\sigma d q)}
\end{aligned}
$$

Perhatikan bahwa $K-(S-P V(q)) e^{\left(r-\frac{1}{2} \sigma^{2}\right)(T-t)+\sigma \sqrt{T-t} X} \geq 0$, diperoleh $X \leq$ $\frac{1}{\sigma \sqrt{T-t}}\left(\ln \left(\frac{k}{S-P V(q)}\right)-\left(r-\frac{1}{2} \sigma^{2}\right)(T-t)\right)$.

Misal $T_{1}=\frac{1}{\sigma \sqrt{T-t}}\left(\ln \left(\frac{k}{S-P V(q)}\right)-\left(r-\frac{1}{2} \sigma^{2}\right)(T-t)\right)$, sehingga $P(S, t)$ pada persamaan (6.9) dapat ditulis menjadi

$P(S, t)=e^{-r(T-t)} \int_{T_{1}}^{\infty} \frac{1}{\sqrt{2 \pi}}\left(K-\left((S-P V(q)) e^{\left(r-\frac{1}{2} \sigma^{2}\right)(T-t)+\sigma \sqrt{T-t} X}\right)\right)^{+} e^{\left.-\frac{x^{2}}{(6 . d} . d x\right)}$

Misalkan $y=x-\sigma \sqrt{T-t}$ maka $x=y-\sigma \sqrt{T-t}$, sehingga $x^{2}=y^{2}+$ $2 y \sigma \sqrt{T-t}+\sigma^{2}(T-t)$ dan $d y=d x$, maka persamaan diatas menjadi

$$
P(S, t)=K e^{-r(\tau-t)}\left(1-N\left(T_{1}\right)\right)-(S-P V(q))\left(1-N\left(T_{1}-\sigma \sqrt{T-t}\right)\right)
$$

Misalkan $T_{1}=d_{2}$ dan $T_{1}-\sigma \sqrt{T-t}=\left(d_{1}\right)$, Sehingga model Black-Scholes opsi put tipe Eropa dengan pembagian dividen pada keadaan constant market adalah

$$
P(S, t)=K e^{-r(\tau-t)} N\left(-d_{2}\right)-(S-P V(q)) N\left(-d_{1}\right)
$$

dimana

$$
d_{1}=\frac{1}{\sigma \sqrt{T-t}}\left(\ln \left(\frac{S-P V(q)}{K}\right)+\left(r+\frac{1}{2} \sigma^{2}\right)(T-t)\right),
$$

dan

$$
d_{2}=d_{1}-\sigma \sqrt{T-t} .
$$

Dengan menggunakan put-call parity dan substitusikan nilai opsi put tipe Eropa dengan pembagian dividen dapat diperoleh model Black-Scholes opsi call tipe Eropa dengan pembagian dividen pada keadaan constant market adalah

$$
C(S, t)=(S-P V(q)) N\left(d_{1}\right)-K e^{-r(T-t)} N\left(d_{2}\right),
$$

dimana

$$
d_{1}=\frac{1}{\sigma \sqrt{T-t}}\left(\ln \left(\frac{S-P V(q)}{K}\right)+\left(r+\frac{1}{2} \sigma^{2}\right)(T-t)\right),
$$


dan

$$
d_{2}=d_{1}-\sigma \sqrt{T-t}
$$

dengan $\sigma$ adalah volatilitas, $S$ adalah harga saham setelah pembagian dividen, $T$ adalah waktu jatuh tempo, $q$ adalah dividen, $t$ adalah waktu ex-dividend, $r$ adalah suku bunga.

\section{Contoh Kasus}

Dalam penelitian ini, data yang digunakan adalah perusahaan Chevron Corporation $(C V X)$ diambil dari www.yahoofinance.com. Studi kasus dalam penelitian ini menggunakan data sekunder harga saham harian Chevron Corporation pada tanggal 18 Desember 2015 sampai dengan tanggal 16 Desember 2016.

\section{Analisis Constant Market}

Berikut akan ditentukan harga opsi call dan opsi put tipe Eropa dengan pembagian dividen pada keadaan constant market Chevron Corpration pada tanggal 16 November 2016. Dari data yang diperoleh dapat diketahui waktu sekarang $(t) 16$ November 2016, waktu jatuh tempo $(T)$ pada tanggal 23 Desember 2016, strike price $(K)=100,101,102,104,105,106,107$ dan 108, harga saham pada tanggal 16 November 2016 yaitu $S_{232}=108.35$, volatilitas sebesar 0.241 , suku bunga diambil dari suku bunga Negara Amerika Serikat (suku bunga Federal Fund) yaitu 0.75, dividen 1.08. Waktu pelaksanaan dipiih pada tanggal 23 Desember 2016, berarti periode waktu hidup opsi adalah 37 hari sehingga $T-t=\frac{37}{365}=0.1$. Nilai-nilai opsi put tipe Eropa dengan pembagian dividen pada keadaan constant market untuk harga pelaksanaan lainnya seperti pada tabel berikut.

\begin{tabular}{|c|c|c|c}
\hline No & $\begin{array}{c}\text { Harga } \\
\text { Pelaksa } \\
\text { naan }\end{array}$ & $\begin{array}{c}\text { Opsi Put } \\
\text { Model } \\
\text { Black- } \\
\text { Scholes }\end{array}$ & $\begin{array}{c}\text { Opsi Put di } \\
\text { Pasar Saham }\end{array}$ \\
\hline 1 & 100 & 0.078 & 0.13 \\
\hline 2 & 101 & 0.95216 & 0.18 \\
\hline 3 & 102 & 1.190 & 0.06 \\
\hline 4 & 104 & 1.809 & 0.13 \\
\hline 5 & 105 & 2.180 & 0.04 \\
\hline 6 & 106 & 2.609 & 0.04 \\
\hline 7 & 107 & 3.083 & 0.03 \\
\hline 8 & 108 & 3.605 & 0.03 \\
\hline
\end{tabular}

\begin{tabular}{|c|c|c|c|}
\hline No & $\begin{array}{c}\text { Harga } \\
\text { Pelaksa } \\
\text { naan }\end{array}$ & $\begin{array}{c}\text { Opsi Call } \\
\text { Model Black- } \\
\text { Scholes }\end{array}$ & $\begin{array}{c}\text { Opsi } \\
\text { Call di } \\
\text { Pasar } \\
\text { Saham }\end{array}$ \\
\hline 1 & 100 & 7.423 & 7.00 \\
\hline 2 & 101 & 7.298 & 6.55 \\
\hline 3 & 102 & 6.537 & 10.34 \\
\hline 4 & 104 & 5.157 & 13.9 \\
\hline 5 & 105 & 4.530 & 8.63 \\
\hline 6 & 106 & 3.959 & 12.05 \\
\hline 7 & 107 & 3.434 & 9.76 \\
\hline 8 & 108 & 2.956 & 10.1 \\
\hline
\end{tabular}

\section{Penutup}

Dilihat dari segi kerugian yang diperoleh, kerugian maksimal yang dialami investor pemegang opsi adalah sebesar harga opsi yang dibayarkan. Sebaliknya, dilihat dari segi keuntungan, yang diperoleh, keuntungan yang maksimal yang diperoleh penjual 
opsi adalah sebesar harga opsi yang diterima, sedangkan kerugian yang mungkin dialami penjual opsi tak terbatas.

\section{Daftar Pustaka}

[1] Anonim.Opsi.https://id.wikipedia.org/wiki/opsi(keuangan). Diakses pada tanggal 09 September 2016 pukul 09:10 WIB

[2] Bain, L.J. 1992. Introduction to Probability and Mathematical Statistic. Ed ke-2. Duxbury Press, California

[3] Black.F, Scholes M. 1973. The Pricing of Options and Corporate liabilities. The Journal of Political Economy

[4] Kishimoto, M. 2008. On the Black-Scholes Equation : Various Derivations. MS and E 408 sTerm Paper

[5] Rahman, A. 2010. Model Black-Scholes Put Call Parity Harga Opsi Tipe Eropa dengan Pembagian Dividen [skripsi]. Surakarta. Jurusan Matematika FMIPA, Universitas Sebelas Maret. 